Article

\title{
Crafting a Sustainable Next Generation Infrastructure: Evaluation of China's New Infrastructure Construction Policies
}

\author{
Jun Wu *D, Yuanjie Zhang and Zhun Shi \\ School of Economics and Management, Beijing University of Posts and Telecommunications, \\ Beijing 100876, China; zhangyuanjie@bupt.edu.cn (Y.Z.); shizhun@bupt.edu.cn (Z.S.) \\ * Correspondence: wujun1127@bupt.edu.cn
}

check for updates

Citation: Wu, J.; Zhang, Y.; Shi, Z. Crafting a Sustainable Next Generation Infrastructure: Evaluation of China's New Infrastructure Construction Policies. Sustainability 2021, 13, 6245. https://doi.org/ $10.3390 /$ su13116245

Academic Editor: Paolo Renna

Received: 5 May 2021

Accepted: 26 May 2021

Published: 1 June 2021

Publisher's Note: MDPI stays neutral with regard to jurisdictional claims in published maps and institutional affiliations.

Copyright: (c) 2021 by the authors. Licensee MDPI, Basel, Switzerland. This article is an open access article distributed under the terms and conditions of the Creative Commons Attribution (CC BY) license (https:// creativecommons.org/licenses/by/ $4.0 /)$.

Abstract: How to boost the economy and achieve more sustainable development with enhanced quality, efficiency, and fairness by leveraging digital technology in the post-COVID-19 era has been an important agenda faced by many countries. As China's new infrastructure initiative has the potential to open a new pathway for economic resilience, its policy characteristics and orientation have attracted more and more attention by policy makers and researchers. Taking the new infrastructure policies issued by Chinese local governments since 2020 as a data source, this paper, on the one hand, uses text mining and social network analysis to reveal the scope and coverage of the construction of new infrastructure and its orientation. On the other hand, a quantitative evaluation of 12 provincial policies grounded on a revised framework and policy modeling consistency index approach was conducted. The results show that Chinese governments adopt a bottom-up incrementalism planning mode for the policy steering of the construction of new infrastructure. This policy arrangement is a kind of goal-oriented modulation that makes planning more adaptive and participatory to enhance the infrastructure sustainability.

Keywords: new infrastructure construction; policy evaluation; policy modeling consistency index; text mining; social network analysis; infrastructure sustainability

\section{Introduction}

The scale of the COVID-19 pandemic's impact and the uncertainty about its future course and consequences are forcing changes in organizational, industrial, and societal fields. Meanwhile, fast development of the new generation of information and communication technology is not only accelerating the growth of the digital industry, but also promoting the deepening of traditional industry digitization. How to facilitate achievement of the Sustainable Development Goals by leveraging digital technology is a key concern for developed and developing countries. The significance of the new infrastructure construction (NIC) has been highlighted by the Chinese government in recent years as the digital transformation of many industries in China has benefited from the comparative advantages of more advanced infrastructure, richer business scenarios, and the larger market scale. In December 2018, the Central Economic Work Conference held by the central government made clear guidance for the promotion of NIC, and those related to 5G commercialization, artificial intelligence, industrial Internet, Internet of Things, and so on were designated as the investments of the new infrastructure. To alleviate the dual impact of COVID-19 and market downturn, the concept of new infrastructure has also for the first time been included in China's Government Work Report for 2020, which vowed to develop next-generation information networks and expand 5G applications, build more charging facilities, promote wider use of new-energy automobiles, stimulate new consumer demand, and promote industrial upgrading. With the new infrastructure initiative rising to the national strategic level, many local governments have issued NIC policies to respond to the central government guidelines and stimulate infrastructure-related investments. As policy text is the reflection and behavior imprint of the government thought and analysis, evaluation of NIC 
policies from China would provide a valuable reference for other countries and regions fighting the pandemic and crafting a sustainable next generation infrastructure.

Current research reveals that, unlike traditional infrastructure, which aims at connecting physical space (highways, bridges, pipelines, and so on), digital technology enables new infrastructure breaks through the limitations of physical space and further expands the connection between the digital world and physical world [1]. NIC is viewed not only as a kind of new investment driven by cutting-edge technology, but also as a new foundation for the digital economy and society [2]. The new infrastructure encourages a fusion between existing physical infrastructure and new digital infrastructure. It not only has the foundational role of the infrastructure, but also has the unique shared, unbounded, heterogeneous, opening, and evolutionary characteristics of the digital infrastructure [3]. Globally, increasing digital infrastructure investment and speeding up of traditional industry digitization have become an important agenda for many countries to boost their economies in the post-COVID-19 epidemic era. In April 2021, U.S. President Joe Biden proposed a domestic infrastructure initiative including upgrading ageing bridges, roads, railways, airports, and urban transit systems, while also expanding and improving the country's digital infrastructure. The significance of this paper lies in the following: (1) The current public policy and planning frameworks in many countries appear inadequately structured to tackle the multifaceted challenges facing infrastructure upgrade in general and sustainable digital infrastructure in particular over the next decades. Unlike a traditional top-down approach to infrastructure planning and spending decision, NIC in China is viewed as a digital technology diffusion and vowed by the central government as an important initiative without detailed conception. A bottom-up approach had been adopted for NIC policy planning and regulation, which allowed local governments to influence the direction as well as the rate of NIC nationwide. Therefore, China's bottom-up NIC-driven approach could provide valuable insights for other countries. (2) As sustainability and infrastructure are intrinsically interconnected, as their common goals are to meet the current and long-term social needs, more research needs to be conducted to examine how the ways in which we select, design, and manage infrastructure today will affect the environment and society for years to come. Existing research on NIC is limited, focusing on its impact on short-term or long-term economy resilience $[4,5]$, and differences with traditional physical infrastructure construction [6,7]. To reduce this research gap, the evaluation of NIC policies issued by local governments might reveal the regional cognitive differences of NIC objectives, scopes, as well as coverages. This paper not only aims to identify the characteristics and orientation of NIC policies, but also enhances our understanding of how Chinese local governments align their regional policies with central government initiatives to craft a sustainable next-generation infrastructure.

The rest of the paper is structured as follows: Prior research and related works are firstly reviewed in Section 2, and an extended framework is also established for NIC policy evaluation. Section 3 delineates policy data sources, as well as the policy modeling consistency index (PMC index) method, and parameter settings for primary and secondary variables. Grounded on text mining and social network analysis approach, Section 4 details the objective and scope of the new infrastructure, and constructs policy keywords and policy object co-occurrence networks to visualize policy focus and its potential orientation. Furthermore, 12 local policies are comparatively evaluated and their characteristics are identified in Section 5. Conclusions, implications, and future directions are drawn in Section 6.

\section{Related Work and Research Framework}

Infrastructure generally describes all physical assets, equipment, and facilities of interrelated systems and the necessary service providers, offering related commodities and services to the public with the aim to enable, sustain, or enhance social living conditions [6]. High quality infrastructure not only opens up new investment opportunity and promotes the expansion of existing business activity for sustainable economic growth, but also im- 
proves the standard of living of people by providing convenient access to essential health and safety resources [6]. Infrastructure construction has the attribute of "quasi-public goods", which is also regarded as a necessity for economic growth and requires the government to play a leading role [4]. Traditional physical infrastructure alludes to material facilities, such as railways, roads, and airports, that provide public services for social and economic activities; it is the foundation of all sectors of the economy. Pervasive use of digital technology in our daily life has led to the evolution of a new species of information technology artefact-digital infrastructure (DI). Although its definition still varies, existing research has adopted the notion of DI as the collection of technological and human components, networks, systems, and processes that contribute to the functioning of organizational or social information systems [7,8]. Driven by digital infrastructure, products, services, and industrial organization are increasingly digitized [9]. As China is scrambling to accelerate the construction of new infrastructure, there have been different interpretations of "new infrastructure", such as "digital infrastructure", "converged infrastructure", and "evolved infrastructure" [2]. In April 2020, the National Development and Reform Commission (NDRC) defined new infrastructure as a new type of infrastructure guided by new development concepts, driven by technological innovation, based on information networks, and oriented toward high-quality development needs, providing digital transformation, intelligent upgrades, integrated innovation, and other services [10,11]. At present, it mainly includes three aspects-information infrastructure on new generation information technology (IT); converged infrastructure aiming upgrading the physical infrastructure with industrial internet, big data, and AI technology; and innovation infrastructure to support research and development for public benefit [5]. According to NDRC, NIC mainly includes 5G base stations, extra-high voltage supply systems, high-speed railways and urban rail systems, new energy vehicle charging points, big data centers, AI, and industrial Internet. It also includes facilitating the digital transformation of industries, as well as integration of innovation services for high quality development. Compared with traditional physical infrastructure, new infrastructure depends more on digital technology and has the characteristics of DI with a layered modular architecture including a devices layer, network layer, service layer, and content layer [7]. From a complex system perspective, new infrastructure is a dynamic and opening social technical system with diversified digital capability, a large number of installed bases, and an engaged community [8,9]. Construction of new infrastructure will not only help China cope with the consequences of the novel coronavirus outbreak, expand domestic demand, and stabilize economic growth and employment in the short term, but also lay a long-term foundation for boosting economic growth, improving people's livelihoods, and sharpening China's competitive edge in global markets [10]. Meanwhile, NIC also provides a market opportunity for incumbents and new entrants to boost regional economies and foster high quality development [11]. Therefore, NIC polices issued by local governments not only guide the pathway of regional infrastructure upgrading, but also push forward the digitalized and intelligent transformation of retail, medical, financial, education, tourism, and other industries in the local area, while enhancing operational efficiency and reducing costs.

Policy evaluation is often used to judge government policy orientation and use an approach to gathering evidence and performing analysis that will be viewed as credible for stakeholders [12]. In general, policy evaluation has three levels: individual policy evaluation, multiple policies or policy system evaluation, and policy provision-policy object-policy background evaluation $[12,13]$. Current researchers evaluate the polices in different fields gradually using multidimensional framework and measures. Using the PMC index approach, Yang et.al [13], evaluated eleven new-energy vehicle industry policies and identified their shortcomings. Grounded on policy objectives, policy tools, and policy implementation framework, Wu et.al [14], conducted a logistic regression analysis to reveal 5G policy differences released by local governments from the eastern, western, and central areas of China. Tang et.al [15], constructed an evaluation framework from the 
perspectives of policy subject (S), policy objectives $(\mathrm{O})$, policy tools $(\mathrm{T})$, and policy actors (A), and made a comparative analysis of the R\&D internationalization policies in China.

We chose the policy framework proposed by Tang et.al for the following reasons. First, considering that the selection of policy evaluation dimension is a process of abstracting specific policy characteristics into evaluation indicators, it is necessary to select the appropriate evaluation framework to identify the advantages and disadvantages of the policy to be evaluated. Second, NIC is a kind of technology that focuses on innovation and diffusion. To examine the alignment of policy tools used by policy subjects with policy targets acted by policy object, Tang et. al's framework is suitable for the research context and can be extended to accommodate more secondary indicators to quantitatively evaluate the policies. Third, to the best of our knowledge, this paper is the first to conduct a comparative evaluation on NIC polices in China. It is necessary to build a rigorous evaluation framework that has been adopted and validated by prior research. We further redesigned the framework shown in Figure 1 to fit the research context in two ways: (1) given the innovative nature of NIC, policy tools need to be aligned with policy objectives to facilitate the infrastructure achievements and application developments [16]; (2) add policy attributes, such as policy time-span and policy rigorous, among others, to reflect the policy characteristics determined by policy objectives and that might have an impact on the policy tools.

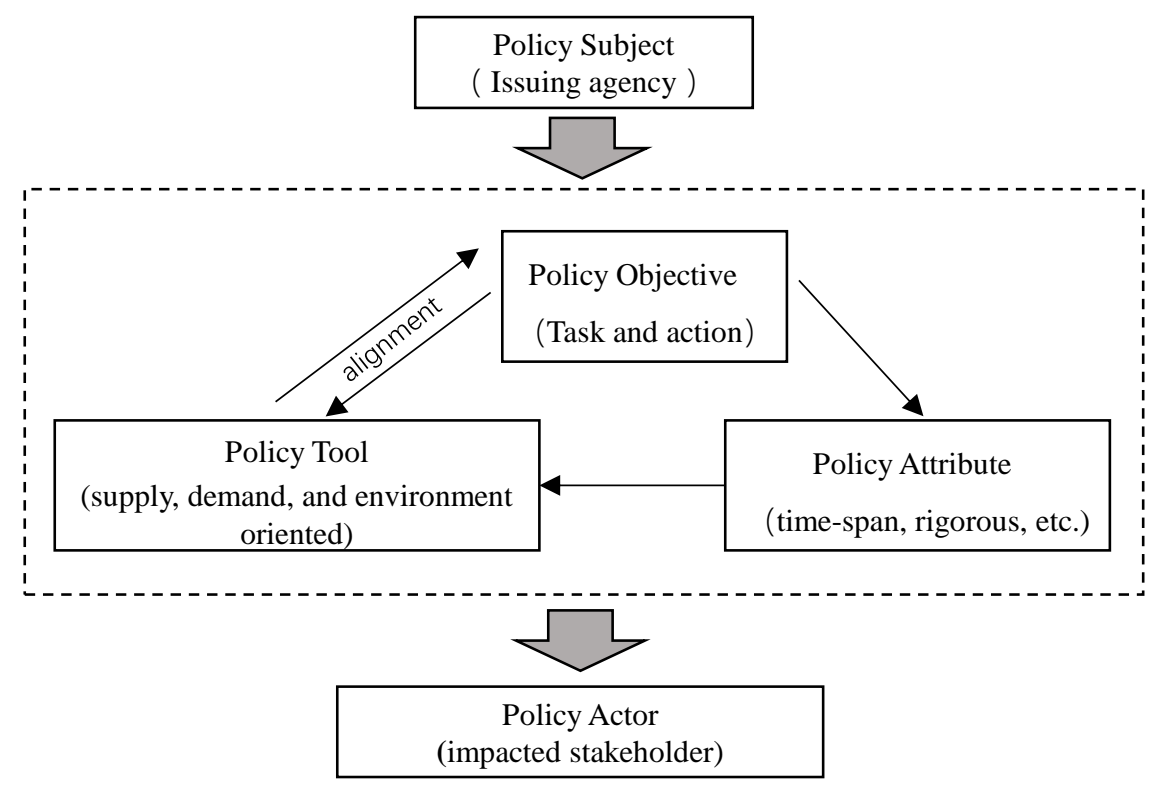

Figure 1. New infrastructure construction (NIC) policy evaluation framework.

As one of the objectives of this research is to evaluate the NIC policies and further identify their shortcomings, an alternative method for evaluation should be comprehensive and the evaluation result needs to be easily interpretable. The PMC index is an analytical tool proposed by Ruiz Estrada to enable policy-makers and researchers to identify strengths or weaknesses of a specific type of policy from a multidimensional perspective [17]. In contrast with other policy evaluation models [18-23], the merits of the PMC index lie in the following factors. First, it is based on the assumption, called the Omnia Mobilis assumption, that believes that, because everything is moving, the policy modeling needs to include more variables without any isolation. Second, the PMC index is a single index transformed by the weighting algorithm with primary and secondary indicators that can be used to evaluate single policy or measure consistencies among a series of policies. Third, it also has the flexibility to facilitate the researchers to find much more suitable indicators and mitigate subject biases based on a context-aware research framework. Last, prior research employed this method in the broad area of policy evaluation and its applicability has been fully validated [23-26]. Thus, it can be applied to conduct the comparison analysis on 
12 local governmental released NIC policies and reflect their differences through PMC index results.

According to Estrada, there are four steps during the construction of the PMC Index. First, selecting the primary variables and secondary variables, and setting the parameter of each variable based on binary identification to evaluate the policy in a multidimensional way. Second, building a multi-input output table to quantify the values of secondary variables. Third, calculating the values of primary variables based on weighted average. Last, constructing the PMC surface to show the strengths and weaknesses of each facet of the policy. Following the procedure, NIC policies issued by different local authorities can be effectively quantified, and their characteristics as well as shortcomings could be identified.

\section{Data Source and Methodology}

\subsection{Policy Data Collection}

In order to collect NIC polices as complete as possible, PKU law library (can be accessed at https: / / www.pkulaw.com/ accessed on 5 May 2021), which is one of the largest Chinese regulation and law databases in China, as well as all local governments' websites, were selected as data sources. The searching and screening criteria were established as follows: (1) policy text title and contents were closely related to the searching keyword like "new infrastructure" and "new infrastructure construction"; (2) policy was released by local authorities; (3) policy texts were regulations and normative documents; and (4) the issuing time period was between 1 January 2017 and 31 December 2020.

A total of 12 policies satisfied all four criteria and were released by provincial level government of China, as shown in Table 1 . Two researchers carefully read through these policy documents and confirmed that the contents meet the research objective. Then, a qualitative analysis of policy texts was conducted and meta data, such as issuing date, issuing agency, and policy title, along with 535 items of policy coding results, such as supply-side incentives, demand-side incentives, safeguard measures, and policy actors, were extracted for further analysis.

Table 1. Overview of new infrastructure construction (NIC) policies issued by 12 local governments.

\begin{tabular}{|c|c|c|c|}
\hline Province & Coding & Policy Title & Issuing Date \\
\hline Jilin & P1 & $\begin{array}{l}\text { Implementation Plan of " } 761 \text { " Project of New Infrastructure } \\
\text { Construction in Jilin }\end{array}$ & 15 April 2020 \\
\hline Shanghai & $\mathrm{P} 2$ & $\begin{array}{l}\text { Action Plan for promoting New Infrastructure Construction in } \\
\text { Shanghai (2020-2022) }\end{array}$ & 29 April 2020 \\
\hline Jiangsu & P3 & $\begin{array}{l}\text { Policies and measures on speeding up the Construction of New } \\
\text { Information Infrastructure and expanding Information consumption }\end{array}$ & 30 April 2020 \\
\hline Beijing & P4 & $\begin{array}{l}\text { Action Plan for speeding up the Construction of New Infrastructure } \\
\text { in Beijing (2020-2022) }\end{array}$ & 10 June 2020 \\
\hline Chongqing & P5 & $\begin{array}{l}\text { Action Plan for the Construction of New Infrastructure Major } \\
\text { projects in Chongqing (2020-2022) }\end{array}$ & 18 June 2020 \\
\hline Zhejiang & P6 & $\begin{array}{l}\text { Three-year Action Plan of New Infrastructure in } \\
\text { Zhejiang Province (2020-2022) }\end{array}$ & 9 July 2020 \\
\hline Fujian & P7 & $\begin{array}{l}\text { Three-year Action Plan of New Infrastructure in } \\
\text { Fujian Province (2020-2022) }\end{array}$ & 5 August 2020 \\
\hline Yunnan & P8 & $\begin{array}{l}\text { Implementation Plan for promoting New Infrastructure Construction } \\
\text { in Yunnan (2020-2022) }\end{array}$ & 5 August 2020 \\
\hline Sichuan & P9 & $\begin{array}{l}\text { Action Plan for speeding up the Construction of New Infrastructure } \\
\text { in Sichuan (2020-2022) }\end{array}$ & 8 September 2020 \\
\hline Hubei & P10 & $\begin{array}{l}\text { Three-year Action Implementation Plan of New Infrastructure Project } \\
\text { for reviving the deficiency and strengthening the function after the } \\
\text { epidemic in Hubei (2020-2022) }\end{array}$ & 17 September 202 \\
\hline Guangdong & P11 & $\begin{array}{l}\text { Three-year Implementation Plan for promoting New Infrastructure } \\
\text { Construction in Guangdong (2020-2022) }\end{array}$ & 12 October 2020 \\
\hline Shandong & P12 & $\begin{array}{l}\text { Three-year Action Plan of New Infrastructure in } \\
\text { Shandong (2020-2022) }\end{array}$ & 2 November 2020 \\
\hline
\end{tabular}




\subsection{PMC Index Modelling Approach}

We structured the evaluation process using PMC index modelling as follows. First, we chose the primary and secondary variables based on the framework shown in Figure 1 to comprehensively cover the dimensions needed to examine the alignment between policy targets and policy actors. Following that, the suitable parameter setting criteria were determined to quantify the different nature of the policies. Second, we built a multi-inputoutput table including all values of secondary variables. Third, we calculated the PMC index for each policy. Last, we constructed the PMC surface and assessed the results for improvement implications.

\subsubsection{Assignment of Variables and Parameter Setting}

Following the framework shown in Figure 1, there was a total of nine primary variables with one variable (issuing agency) designed for measuring policy subject, one variable (construction domain) designated for policy objective, three variables (supply-side incentives, demand-side incentives, and safeguard measures) assigned for policy tools, one variable (targeted actor) selected for policy actors, and the remaining three variables (policy time-span, policy type, and policy rigorous) chosen for policy attributes. To select the appropriate second-level measuring indicator and its parameter setting, two researchers first carefully checked the policy coding results mentioned in Section 2, and some potential candidates were elicited. After two rounds of discussions with domain policy researchers and subject matter experts, 43 secondary variables corresponding to nine primary variables were finally decided. Their meanings and settings are shown in Table 2.

Table 2. Policy modeling consistency (PMC) index model variables and parameter settings of NIC policy.

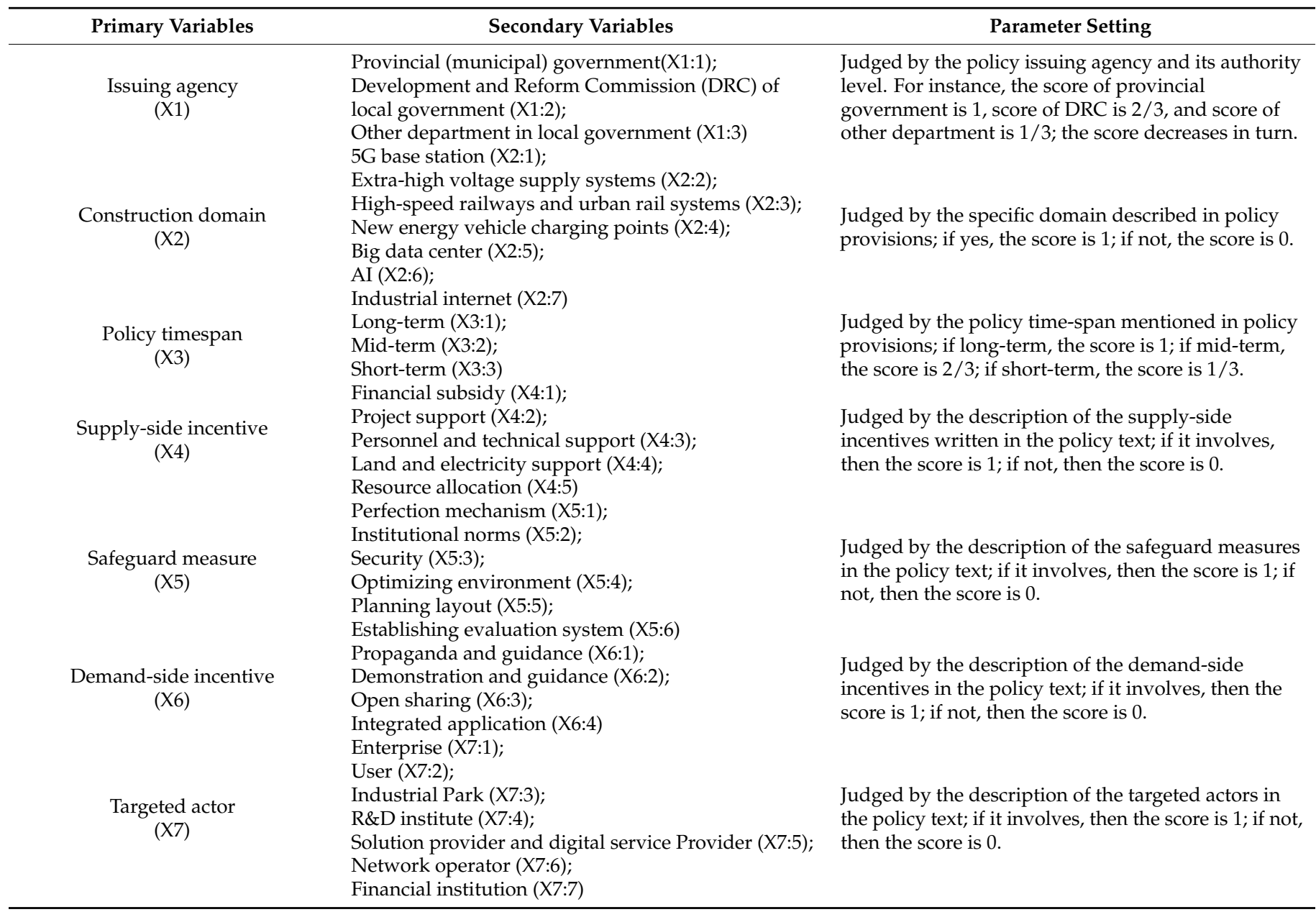


Table 2. Cont.

\begin{tabular}{|c|c|c|}
\hline Primary Variables & Secondary Variables & Parameter Setting \\
\hline $\begin{array}{l}\text { Policy type } \\
\quad(\mathrm{X} 8)\end{array}$ & $\begin{array}{l}\text { Planning (X8:1); } \\
\text { Recommending (X8:2); } \\
\text { Designing (X8:3); } \\
\text { Guiding (X8:4); } \\
\text { Supervising (X8:5) }\end{array}$ & $\begin{array}{l}\text { Judged by the contents of the policy provision; if it } \\
\text { involves, then the score is } 1 \text {; if not, then the score is } 0 .\end{array}$ \\
\hline $\begin{array}{l}\text { Policy rigorous } \\
\text { (X9) }\end{array}$ & $\begin{array}{l}\text { Measurable action }(X 9: 1) \\
\text { Sound justification }(X 9: 2) \\
\text { Clear role and responsibility classification (X9:3) }\end{array}$ & $\begin{array}{l}\text { Judged by the policy coding results; if it involves, } \\
\text { then the score is } 1 \text {; if not, then the score is } 0 \text {. }\end{array}$ \\
\hline
\end{tabular}

\subsubsection{Building a Multi-Input-Output Table}

A multi-input-output table provides an analytical framework and template for the calculation of primary variables. It has the characteristics of convenient storage of many data and attribution of multi-dimensional variables to a single variable [27]. A multi-inputoutput table is established based on 9 primary variables and 43 secondary variables shown in Table 3. Each primary variable and secondary variable has the same weight.

Table 3. Multi-input-output table.

\begin{tabular}{cc}
\hline Primary Variables & Secondary Variables \\
\hline $\mathrm{X} 1$ & $\mathrm{X} 1: 1, \mathrm{X} 1: 2, \mathrm{X} 1: 3$ \\
$\mathrm{X} 2$ & $\mathrm{X} 2: 1, \mathrm{X} 2: 2, \mathrm{X} 2: 3, \mathrm{X} 2: 4, \mathrm{X} 2: 5, \mathrm{X} 2: 6, \mathrm{X} 2: 7$ \\
$\mathrm{X} 3$ & $\mathrm{X} 3: 1, \mathrm{X} 3: 2, \mathrm{X} 3: 3$ \\
$\mathrm{X} 4$ & $\mathrm{X} 4: 1, \mathrm{X} 4: 2, \mathrm{X} 4: 3, \mathrm{X} 4: 4, \mathrm{X} 4: 5$ \\
$\mathrm{X} 5$ & $\mathrm{X} 5: 1, \mathrm{X} 5: 2, \mathrm{X} 5: 3, \mathrm{X} 5: 4, \mathrm{X} 5: 5, \mathrm{X} 5: 6$ \\
$\mathrm{X} 6$ & $\mathrm{X} 7: 1, \mathrm{X} 7: 2, \mathrm{X} 7: 3: \mathrm{X} 7: 4, \mathrm{X} 7: 5, \mathrm{X} 7: 6, \mathrm{X} 7: 7$ \\
$\mathrm{X} 7$ & $\mathrm{X} 8: 1, \mathrm{X} 8: 2, \mathrm{X} 8: 3, \mathrm{X} 8: 4, \mathrm{X} 8: 5$ \\
$\mathrm{X} 8$ & $\mathrm{X} 9: 1, \mathrm{X} 9: 2, \mathrm{X} 9: 3$ \\
\hline
\end{tabular}

\subsubsection{PMC Index Calculation}

As proposed by Estrada [27], the PMC index calculation follows a structured procedure as follows:

First, the PMC index model with 9 primary variables and 43 secondary variables designed for NIC policy evaluation is incorporated into the multi-input-output table, and the secondary variables are assigned according to Equation (1) and Equation (2), respectively.

$$
\begin{gathered}
X \sim N[0 \sim 1] \\
X=\{X R:[0 \sim 1]\}
\end{gathered}
$$

Second, the nine primary variable values are calculated according to Equation (3).

$$
X_{i}\left[\sum_{j=1}^{n} \frac{X_{i j}}{T\left(X_{i j}\right)}\right]
$$

$\mathrm{i}, \mathrm{j}=1,2,3, \ldots, \mathrm{n}$, i denotes a primary variable, while $\mathrm{j}$ denotes a secondary variable.

$$
P M C=\left[\begin{array}{l}
X_{1}\left[\sum_{a=1}^{3} \frac{X_{1 a}}{3}\right]+X_{2}\left[\sum_{b=1}^{7} \frac{X_{2 b}}{7}\right]+X_{3}\left[\sum_{c=1}^{3} \frac{X_{3 c}}{3}\right]+ \\
X_{4}\left[\sum_{d=1}^{5} \frac{X_{4 d}}{5}\right]+X_{5}\left[\sum_{e=1}^{5} \frac{X_{5 e}}{5}\right]+X_{6}\left[\sum_{\mathrm{f}=1}^{5} \frac{X_{6 f}}{5}\right]+ \\
X_{7}\left[\sum_{g=1}^{7} \frac{X_{7 g}}{7}\right]+X_{8}\left[\sum_{h=1}^{5} \frac{X_{8 h}}{5}\right]+X_{9}\left[\sum_{k=1}^{3} \frac{X_{9 k}}{3}\right]
\end{array}\right]
$$


Last, the PMC index of each individual NIC policy can be calculated using Equation (4).

\subsubsection{Policy Grading and Evaluation}

Referenced with the evaluation standard designed by Estrada [27] and similar research $[23,24]$, the results of the PMC index score range from 0 to 9 . The larger the value of the score, the more comprehensive the consideration of the policy, leading to much easier operation in practice. Policy score grade and its corresponding evaluation are shown in Table 4.

Table 4. Policy grade evaluation based on the PMC index.

\begin{tabular}{ccccc}
\hline Score & $\mathbf{8 - 9 . 0}$ & $6-7.9$ & $4-5.9$ & $0-3.9$ \\
\hline Evaluation & Perfect & Excellent & Acceptable & Poor \\
\hline
\end{tabular}

\subsubsection{PMC Surface Construction}

The PMC surface visualizes the PMC index score in a multi-dimensional way and can display the strengths and weakness of each NIC policy. As construction of the PMC surface depends on the calculation of the PMC matrix, the corresponding formula is shown in Equation (5).

$$
\operatorname{PMC}(\text { surface })=\left[\begin{array}{lll}
X_{1} & X_{2} & X_{3} \\
X_{4} & X_{5} & X_{6} \\
X_{7} & X_{8} & X_{9}
\end{array}\right]
$$

\section{Policy Objective and Orientation Analysis}

\subsection{Policy Objective and Scope}

As government can influence the rate and direction of the innovation diffusion, policy objective defines the commitment and goal of the construction of new infrastructure. Through carefully reading the corresponding paragraphs of 12 provincial policy documents, the main areas and subareas of new infrastructure, as well as their occurrence frequencies, were identified. A Sankey diagram is drawn in Figure 2.

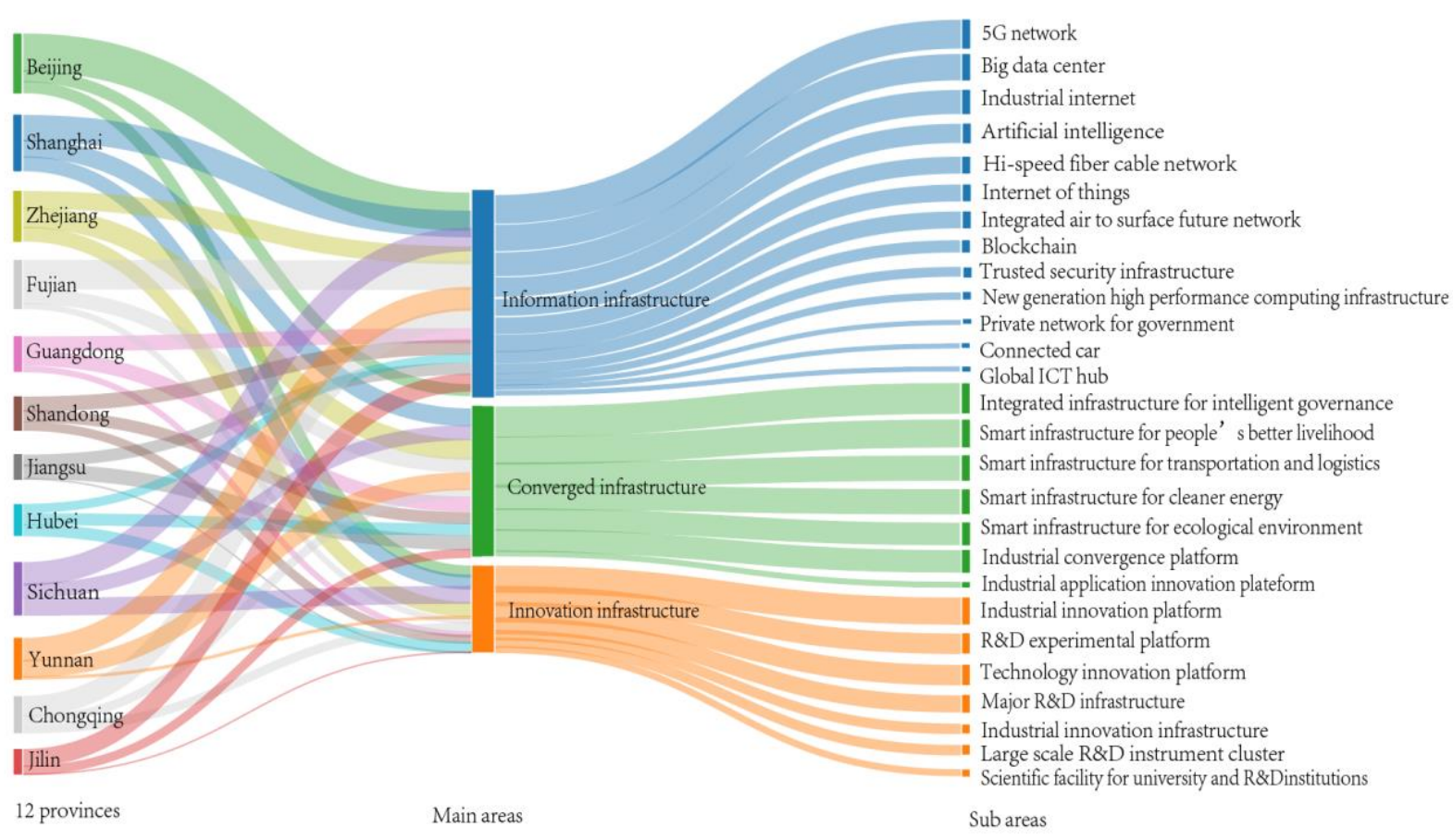

Figure 2. NIC main areas and subareas identified in 12 provincial policies. 
Although the Chinese central government defined the three main areas of new infrastructure as information infrastructure, converged infrastructure, and innovation infrastructure, it can be shown in Figure 2 that the objectives defined in 12 local governments polices were more focused on information infrastructure and converged infrastructure, with less mention of innovation infrastructure. Meanwhile, given that development gaps existed among different regions of China, there are obviously cognitive differences in the connotation and requirements of NIC subareas. For example, besides the communication infrastructure, such as 5G, Internet of Things, and industrial Internet defined by NDRC, local governments in developed areas, such as Beijing and Shanghai, specified the construction of private network, global information and communication hubs, and integrated air to surface future networks to enhance their pervasive connectivity. Local authorities in developing areas, like Sichuan and Hubei, vowed to invest in scientific research experiment, technological innovation, and industrial innovation platform to promote the local R\&D and innovation capabilities. This indicates that the construction of new infrastructure is a dynamic social-technical process of co-evolution, which involves variation and progressive social change. Local authorities had to be responsive to select, organize, and structure the appropriate governance styles and tools to meet the requirement of regional sustainable development.

\subsection{Policy Keyword Co-Occurrence Analysis}

Existing research on policy texts analysis focuses on keyword extraction and keyword cloud visualization $[28,29]$. In order to investigate the hidden relationship between high frequency keywords and further reveal the policy orientation, keyword co-occurrence analysis was conducted following a structured process. First, python code was used to automatically find NIC-domain specific terms from 12 Chinese policy texts and build the copra as the basis for Chinese word segmentation. Second, open-source library Jieba in $\mathrm{R}$ programming was used to effectively divide Chinese paragraphs and sentences into 36 meaningful token level high frequency keywords. Last, a keyword co-occurrence matrix with word segmentation results was constructed and, finally, a graph of NIC policy keyword co-occurrence network was generated as shown in Figure 3.

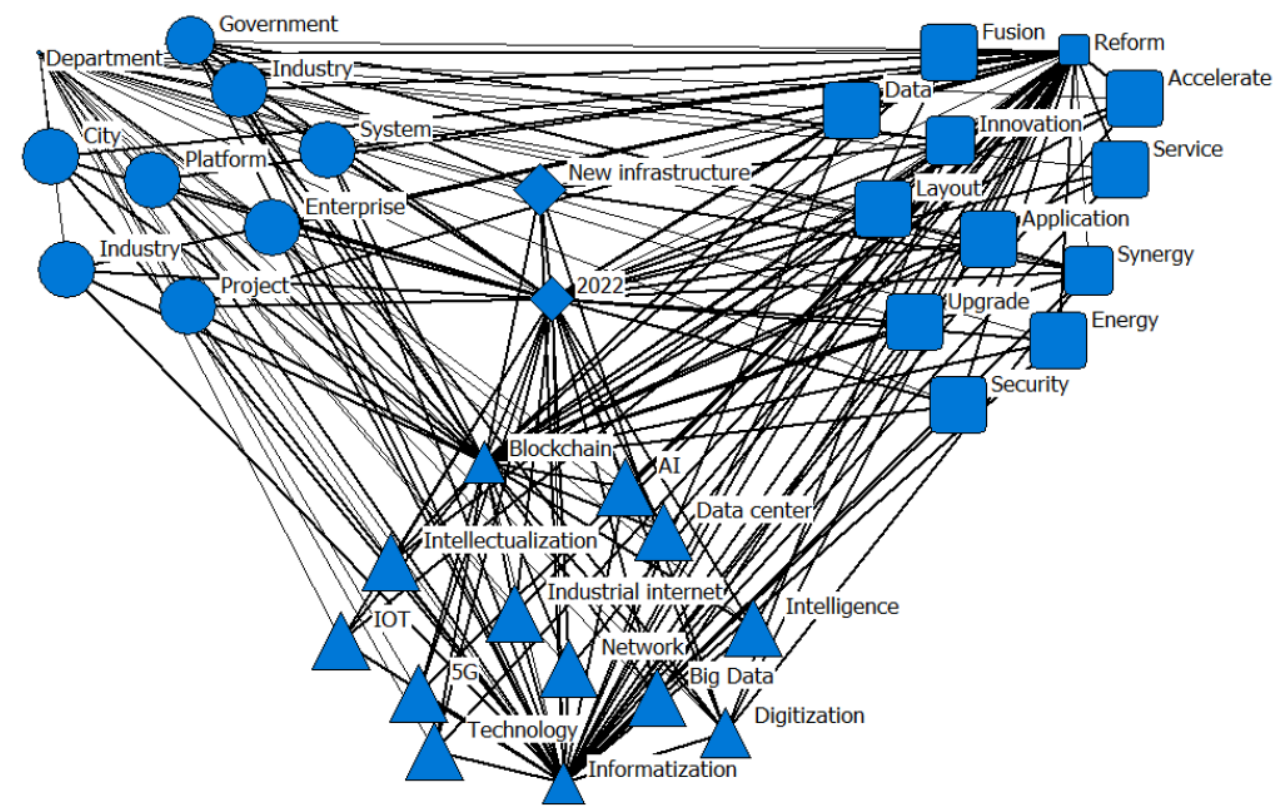

Figure 3. NIC policy keyword co-occurrence network.

Nodes in Figure 3 represent the keyword, and edges in the network represent the links between keywords. Node size reflects the frequency of the keyword, while edge thickness reflects the frequency of the co-occurrence of the keyword-pair. In addition, node shape 
denotes the keywords cluster with close semantic similarity and node position indicates keyword centrality within the network. Figure 2 shows that 36 NIC policy keywords can be grouped into three distinct clusters: technology domain-related, attribute-related, and stakeholder-related. Four policy orientation characteristics can be inferred from the network. First, graph nodes of "new infrastructure" and the year of 2022 locates in the network center, implying that most local governments implement the NIC with threeyear time periods and set the year 2022 as the phase due time. Second, the closeness among emerging new technologies, such as 5G, big data, AI, industrial Internet, and so on, reveals that digitalization and intelligence have become key for new infrastructure and, DI plays a crucial role in the construction of new infrastructure. Third, keywords like "convergence", "security", and "layout" locate close to the center of the network, reflecting the importance of security self-control when speeding up the rollout of new infrastructure and convergence impetus to empower traditional industry. Last, keywords such as "government", "city", "platform", and "industry" are still close to the network center, suggesting that the government would guide the construction of new infrastructure, smart city construction would change the regional landscape, the platform would be the emerging new organizational form, and industry transformation would be accompanied by the infrastructure upgrading.

\subsection{Policy Object Co-Occurrence Network Analysis}

Policy object is generally viewed as policy-actors who enact polices within policy discourses [30]. As NIC policy involves different stakeholders from R\&D and financial institutions, business organizations, and talented experts, among others, the co-occurrence network analysis on policy object could visualize interactions among engaged participants and examine potential mechanisms that determine the importance of the role each actor plays [31]. A structured analysis process was conducted following three steps. First, two researchers went through the contents of 12 policies, and manually labeled the policy actors independently to mitigate coding subjective bias. Second, to assure the intercoder reliability, the fleiss' Kappa analysis was conducted and two coders shared a higher level of agreement (Kappa $=0.85, p \leq 0.01)$. All disagreements in policy object coding were consensually coded. Third, two researchers merged some semantically similar actors (for example, merged universities and R\&D center into R\&D institutions), and constructed the policy object co-occurrence matrix. Finally, the graph of co-occurrence network for 12 NIC policies was drawn, as shown in Figure 4.

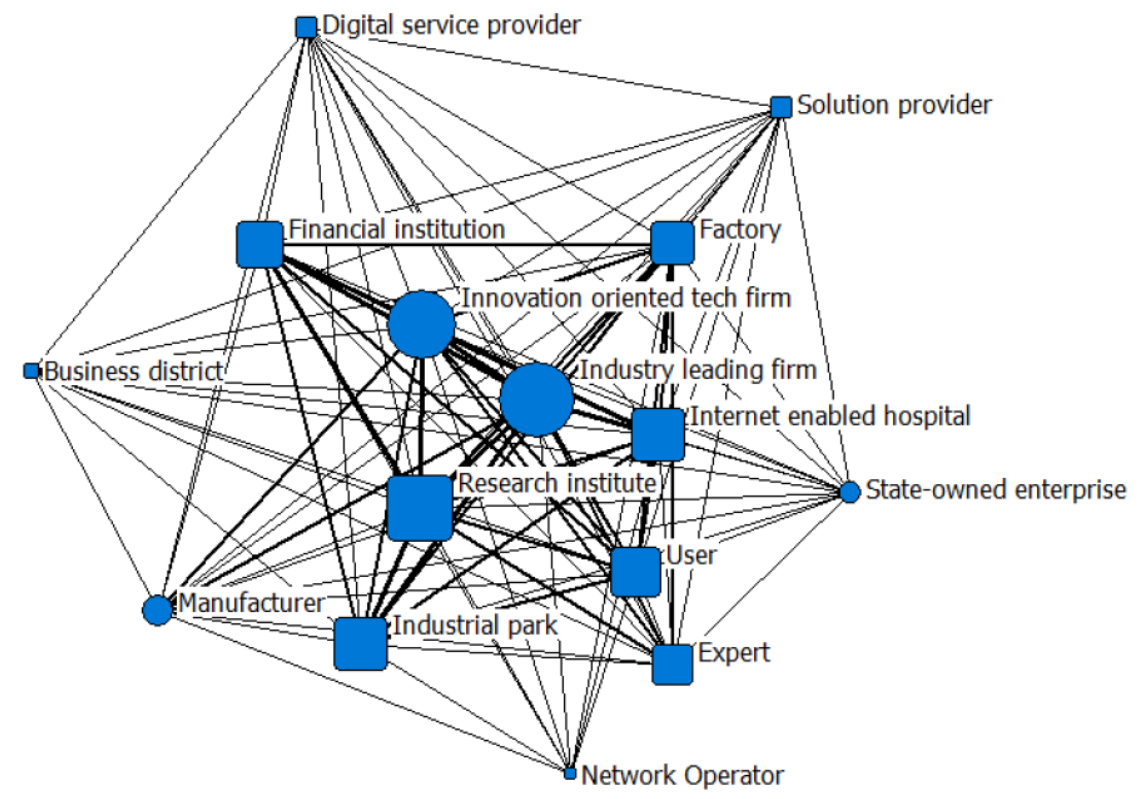

Figure 4. Co-occurrence network for 12 NIC policies. 
Both network centrality calculations and node positions in Figure 4 show that industry leading firms, innovation focused tech firms, R\&D institutions, and industrial park locate at the heart of the network and rank in the top four based on their centrality contribution. This implies that, on the one hand, local governments attribute important roles to industrial giants and tech companies, and expect them to be key contributors to the achievements of new infrastructure. On the other hand, as there are considerable bottlenecks for technology breakthrough during the construction of new infrastructure, local government also emphasizes the enabling roles that these firms play to facilitate technology diffusion and application innovation. Moreover, industrial park is another focus of NIC as there is a need to integrate digital technology with the local industries and eco-system to successfully build a smart industrial park and promote the fusion of online and offline activities. It should also be noted that policy actors, such as digital service providers, solution providers, and manufacturers, among others, locate at the peripheral of the network, indicating a low frequency of mentions in the policy texts. More directions should be provided to build a digital ecosystem of new infrastructure integrating coordinated development of upstream and downstream industry players.

\section{NIC Policy Evaluation and Discussion}

\subsection{PMC Index of 12 NIC Policies}

Based on the PMC model variables and parameter settings outlined in Table 2, the secondary variable values and PMC index scores of each of the 12 policies were calculated, as shown in Tables 5 and 6, respectively.

Table 5. Twelve multi-input-output tables of new infrastructure policies.

\begin{tabular}{|c|c|c|c|c|c|c|c|c|c|c|c|c|c|}
\hline & & P1 & P2 & P3 & P4 & P5 & P6 & P7 & P8 & P9 & P10 & P11 & P12 \\
\hline & X1:1 & 1 & 1 & 1 & 0 & 1 & 1 & 1 & 1 & 1 & 1 & 1 & 1 \\
\hline \multirow[t]{5}{*}{ X1 } & $\mathrm{X} 1: 2$ & 0 & 1 & 1 & 0 & 1 & 1 & 1 & 1 & 1 & 1 & 1 & 1 \\
\hline & X1:3 & 1 & 1 & 1 & 1 & 1 & 1 & 1 & 1 & 1 & 1 & 1 & 1 \\
\hline & X2:1 & 1 & 1 & 1 & 1 & 1 & 1 & 1 & 1 & 1 & 1 & 1 & 1 \\
\hline & X2:2 & 1 & 0 & 0 & 0 & 0 & 1 & 0 & 0 & 1 & 0 & 0 & 1 \\
\hline & $X 2: 3$ & 1 & 1 & 0 & 0 & 0 & 1 & 1 & 0 & 1 & 1 & 0 & 1 \\
\hline \multirow{5}{*}{$\mathrm{X} 2$} & X2:4 & 1 & 1 & 1 & 1 & 1 & 1 & 1 & 1 & 1 & 0 & 1 & 1 \\
\hline & X2:5 & 1 & 1 & 1 & 1 & 1 & 1 & 1 & 1 & 1 & 1 & 1 & 1 \\
\hline & X2:6 & 1 & 1 & 1 & 1 & 1 & 1 & 1 & 1 & 1 & 1 & 1 & 1 \\
\hline & X2:7 & 1 & 1 & 1 & 1 & 1 & 1 & 1 & 1 & 1 & 1 & 1 & 1 \\
\hline & X3:1 & 1 & 0 & 0 & 0 & 0 & 0 & 0 & 0 & 0 & 0 & 0 & 0 \\
\hline \multirow[t]{4}{*}{ X3 } & X3:2 & 0 & 1 & 0 & 1 & 1 & 1 & 1 & 1 & 1 & 1 & 1 & 1 \\
\hline & X3:3 & 0 & 0 & 1 & 0 & 0 & 0 & 0 & 0 & 0 & 0 & 0 & 0 \\
\hline & $X 4: 1$ & 1 & 1 & 1 & 1 & 1 & 1 & 1 & 1 & 1 & 1 & 1 & 1 \\
\hline & $X 4: 2$ & 0 & 1 & 1 & 0 & 1 & 1 & 1 & 1 & 0 & 1 & 1 & 1 \\
\hline \multirow[t]{5}{*}{$\mathrm{X} 4$} & $X 4: 3$ & 0 & 0 & 1 & 1 & 0 & 1 & 1 & 0 & 1 & 0 & 0 & 1 \\
\hline & $X 4: 4$ & 0 & 1 & 1 & 1 & 1 & 1 & 1 & 1 & 1 & 1 & 1 & 1 \\
\hline & $X 4: 5$ & 1 & 1 & 1 & 1 & 1 & 1 & 1 & 1 & 1 & 1 & 1 & 1 \\
\hline & X5:1 & 1 & 1 & 0 & 1 & 1 & 1 & 1 & 1 & 1 & 1 & 1 & 1 \\
\hline & X5:2 & 1 & 1 & 1 & 1 & 1 & 1 & 0 & 0 & 1 & 1 & 1 & 1 \\
\hline \multirow[t]{5}{*}{ X5 } & X5:3 & 0 & 1 & 1 & 1 & 1 & 1 & 1 & 1 & 1 & 1 & 1 & 1 \\
\hline & X5:4 & 0 & 1 & 1 & 1 & 1 & 1 & 1 & 1 & 0 & 1 & 1 & 1 \\
\hline & X5:5 & 0 & 1 & 0 & 1 & 1 & 1 & 1 & 1 & 1 & 1 & 1 & 1 \\
\hline & X6:1 & 0 & 1 & 1 & 1 & 1 & 0 & 1 & 1 & 1 & 1 & 1 & 1 \\
\hline & X6:2 & 1 & 1 & 1 & 1 & 1 & 1 & 1 & 1 & 1 & 0 & 1 & 1 \\
\hline \multirow[t]{3}{*}{ X6 } & X6:3 & 0 & 1 & 1 & 1 & 1 & 1 & 1 & 1 & 1 & 0 & 1 & 1 \\
\hline & X6:4 & 0 & 1 & 1 & 1 & 1 & 1 & 1 & 1 & 1 & 1 & 1 & 1 \\
\hline & X6:5 & 0 & 1 & 0 & 1 & 1 & 1 & 1 & 1 & 1 & 0 & 1 & 1 \\
\hline
\end{tabular}


Table 5. Cont

\begin{tabular}{|c|c|c|c|c|c|c|c|c|c|c|c|c|c|}
\hline & & P1 & P2 & P3 & P4 & P5 & P6 & P7 & P8 & P9 & P10 & P11 & P12 \\
\hline \multirow{8}{*}{ X7 } & $X 7: 1$ & 1 & 1 & 1 & 1 & 1 & 1 & 1 & 1 & 1 & 1 & 1 & 1 \\
\hline & $X 7: 2$ & 0 & 1 & 1 & 1 & 1 & 1 & 1 & 1 & 0 & 0 & 1 & 0 \\
\hline & $X 7: 3$ & 1 & 1 & 0 & 1 & 1 & 0 & 1 & 1 & 1 & 1 & 1 & 1 \\
\hline & $X 7: 4$ & 0 & 1 & 0 & 1 & 1 & 1 & 1 & 1 & 1 & 1 & 1 & 1 \\
\hline & $X 7: 5$ & 0 & 0 & 1 & 1 & 0 & 0 & 0 & 0 & 0 & 0 & 0 & 0 \\
\hline & $X 7: 6$ & 0 & 1 & 0 & 0 & 1 & 0 & 0 & 0 & 0 & 0 & 1 & 0 \\
\hline & $X 7: 7$ & 1 & 1 & 0 & 0 & 1 & 1 & 0 & 1 & 1 & 1 & 1 & 1 \\
\hline & X8:1 & 1 & 1 & 1 & 1 & 1 & 1 & 1 & 1 & 1 & 1 & 1 & 1 \\
\hline \multirow{4}{*}{ X8 } & X8:2 & 0 & 1 & 1 & 1 & 1 & 1 & 1 & 1 & 1 & 1 & 1 & 1 \\
\hline & X8:3 & 1 & 1 & 1 & 1 & 1 & 1 & 1 & 1 & 1 & 1 & 1 & 1 \\
\hline & $X 8: 4$ & 1 & 1 & 1 & 1 & 1 & 1 & 1 & 1 & 1 & 1 & 1 & 1 \\
\hline & X8:5 & 1 & 1 & 1 & 1 & 1 & 1 & 1 & 1 & 1 & 1 & 1 & 1 \\
\hline \multirow{3}{*}{ X9 } & X9:1 & 1 & 1 & 1 & 1 & 1 & 1 & 1 & 1 & 1 & 1 & 1 & 1 \\
\hline & X9:2 & 1 & 1 & 0 & 0 & 1 & 1 & 1 & 1 & 1 & 0 & 1 & 1 \\
\hline & X9:3 & 1 & 1 & 1 & 1 & 1 & 1 & 0 & 0 & 1 & 1 & 1 & 1 \\
\hline
\end{tabular}

Table 6. PMC index of 12 new infrastructure policies.

\begin{tabular}{ccccccccccc}
\hline & $\mathbf{X 1}$ & $\mathbf{X} \mathbf{X}$ & $\mathbf{X 3}$ & $\mathbf{X} \mathbf{1}$ & $\mathbf{X 5}$ & $\mathbf{X 6}$ & $\mathbf{X 7}$ & $\mathbf{X 8}$ & $\mathbf{X 9}$ & PMC Index \\
\hline P1 & 1.00 & 1.00 & 0.33 & 0.60 & 0.40 & 0.20 & 0.43 & 0.8 & 1.00 & 5.76 \\
P2 & 1.00 & 0.86 & 0.33 & 0.80 & 1.00 & 1.00 & 0.86 & 1.00 & 1.00 & 7.85 \\
P3 & 1.00 & 0.71 & 0.33 & 1.00 & 0.60 & 0.80 & 0.43 & 1.00 & 0.67 & 6.54 \\
P4 & 0.33 & 0.71 & 0.33 & 0.80 & 1.00 & 1.00 & 0.71 & 1.00 & 0.67 & 6.55 \\
P5 & 1.00 & 0.71 & 0.33 & 1.00 & 1.00 & 1.00 & 0.57 & 1.00 & 0.33 & 6.94 \\
P6 & 1.00 & 1.00 & 0.33 & 1.00 & 1.00 & 0.80 & 0.57 & 1.00 & 1.00 & 7.70 \\
P7 & 1.00 & 0.86 & 0.33 & 1.00 & 0.80 & 1.00 & 0.57 & 1.00 & 0.67 & 7.23 \\
P8 & 1.00 & 0.71 & 0.33 & 0.80 & 0.80 & 1.00 & 0.71 & 1.00 & 0.67 & 7.02 \\
P9 & 1.00 & 1.00 & 0.33 & 0.80 & 0.80 & 1.00 & 0.57 & 1.00 & 1.00 & 7.50 \\
P10 & 1.00 & 0.71 & 0.33 & 0.80 & 1.00 & 0.40 & 0.57 & 1.00 & 0.67 & 6.48 \\
P11 & 1.00 & 0.71 & 0.33 & 0.80 & 1.00 & 1.00 & 0.86 & 1.00 & 1.00 & 7.70 \\
P12 & 1.00 & 1.00 & 0.33 & 1.00 & 1.00 & 1.00 & 0.57 & 1.00 & 1.00 & 7.90 \\
Average & 0.94 & 0.83 & 0.33 & 0.87 & 0.87 & 0.85 & 0.62 & 0.98 & 0.81 & 7.04 \\
\hline
\end{tabular}

As can be seen from the results of the PMC index in Table 7, the average PMC index score of 12 NIC policies is 7.10, of which 11 are excellent and 1 is acceptable, indicating that NIC policies issued by most provincial governments are more comprehensive in consideration and reasonable in design. Specifically, Shandong Province has the highest score of PMC index, while Jilin Province has a lower score of 5.76. From a regional point of view, the eastern provinces, like Shandong, Shanghai, and Zhejiang, are relatively near the top, while the provinces in western and central regions follow closely.

Table 7. Grade evaluation of 12 new infrastructure policies.

\begin{tabular}{|c|c|c|c|c|c|}
\hline Province & Policy Title & Primary Variable & PMC Index & Rank & Evaluation \\
\hline Shandong & $\begin{array}{l}\text { Three-year Action Plan of New Infrastructure in } \\
\text { Shandong (2020-2022) }\end{array}$ & $\mathrm{P} 12$ & 7.90 & 1 & Excellent \\
\hline Shanghai & $\begin{array}{l}\text { Action Plan for promoting New Infrastructure } \\
\text { Construction in Shanghai (2020-2022) }\end{array}$ & P2 & 7.85 & 2 & Excellent \\
\hline Zhejiang & $\begin{array}{l}\text { Three-year Action Plan of New Infrastructure in } \\
\text { Zhejiang Province (2020-2022) }\end{array}$ & P6 & 7.70 & 3 & Excellent \\
\hline Guangdong & $\begin{array}{l}\text { Three-year Implementation Plan for promoting } \\
\text { New Infrastructure Construction in } \\
\text { Guangdong (2020-2022) }\end{array}$ & P11 & 7.50 & 4 & Excellent \\
\hline Sichuan & $\begin{array}{l}\text { Action Plan for speeding up the Construction of } \\
\text { New Infrastructure in Sichuan }(2020-2022)\end{array}$ & P9 & 7.50 & 5 & Excellent \\
\hline Fujian & $\begin{array}{l}\text { Three-year Action Plan of New Infrastructure in } \\
\text { Fujian Province (2020-2022) }\end{array}$ & P7 & 7.23 & 6 & Excellent \\
\hline
\end{tabular}


Table 7. Cont.

\begin{tabular}{|c|c|c|c|c|c|}
\hline Province & Policy Title & Primary Variable & PMC Index & Rank & Evaluation \\
\hline Yunnan & $\begin{array}{l}\text { Implementation Plan for promoting New } \\
\text { Infrastructure Construction in Yunnan (2020-2022) }\end{array}$ & P8 & 7.02 & 7 & Excellent \\
\hline Chongqing & $\begin{array}{l}\text { Action Plan for the Construction of New } \\
\text { Infrastructure Major projects in } \\
\text { Chongqing (2020-2022) }\end{array}$ & P5 & 6.94 & 8 & Excellent \\
\hline Beijing & $\begin{array}{l}\text { Action Plan for speeding up the Construction of } \\
\text { New Infrastructure in Beijing (2020-2022) } \\
\text { Policies and measures on speeding up the }\end{array}$ & P4 & 6.55 & 9 & Excellent \\
\hline Jiangsu & $\begin{array}{l}\text { Construction of New Information Infrastructure and } \\
\text { expanding Information consumption }\end{array}$ & P3 & 6.54 & 10 & Excellent \\
\hline Hubei & $\begin{array}{l}\text { Three-year Action Implementation Plan of New } \\
\text { Infrastructure Project for reviving the deficiency and } \\
\text { strengthening the function after the epidemic in } \\
\text { Hubei (2020-2022) }\end{array}$ & P10 & 6.48 & 11 & Excellent \\
\hline Jilin & $\begin{array}{l}\text { Implementation Plan of " } 761 \text { " Project of New } \\
\text { Infrastructure Construction in Jilin }\end{array}$ & P1 & 5.76 & 12 & Acceptable \\
\hline
\end{tabular}

\subsection{PMC Surface Analysis of 12 NIC Policies}

Owing to space limitations, the PMC surfaces for rank \#1 (P12) and rank \#12 (P1) are shown in Figures 5 and 6, respectively. Through the comparison of the depression degree of the two PMC surfaces, we can directly judge the advantages and disadvantages of NIC policies issued by different local governments.

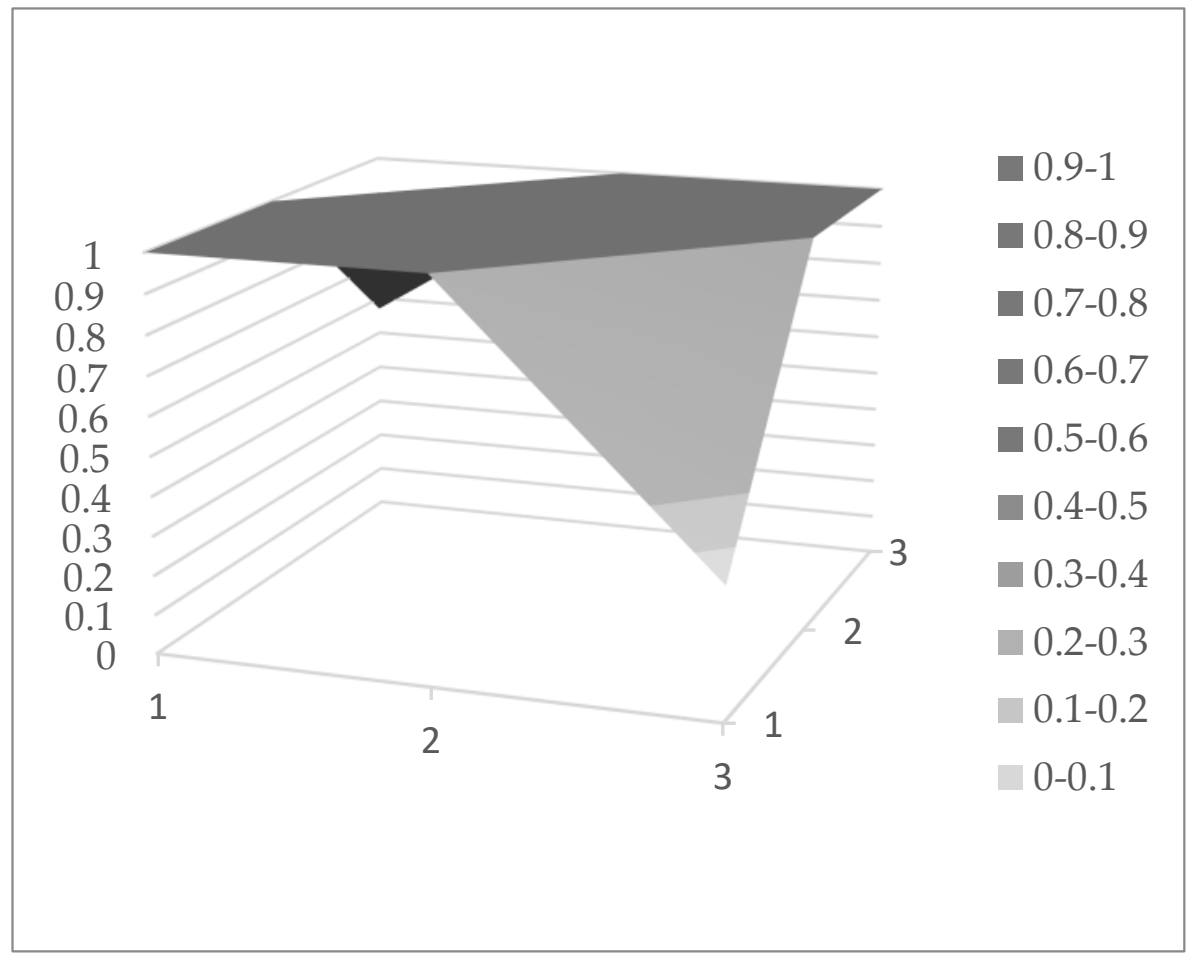

Figure 5. PMC surface of policy P12. 


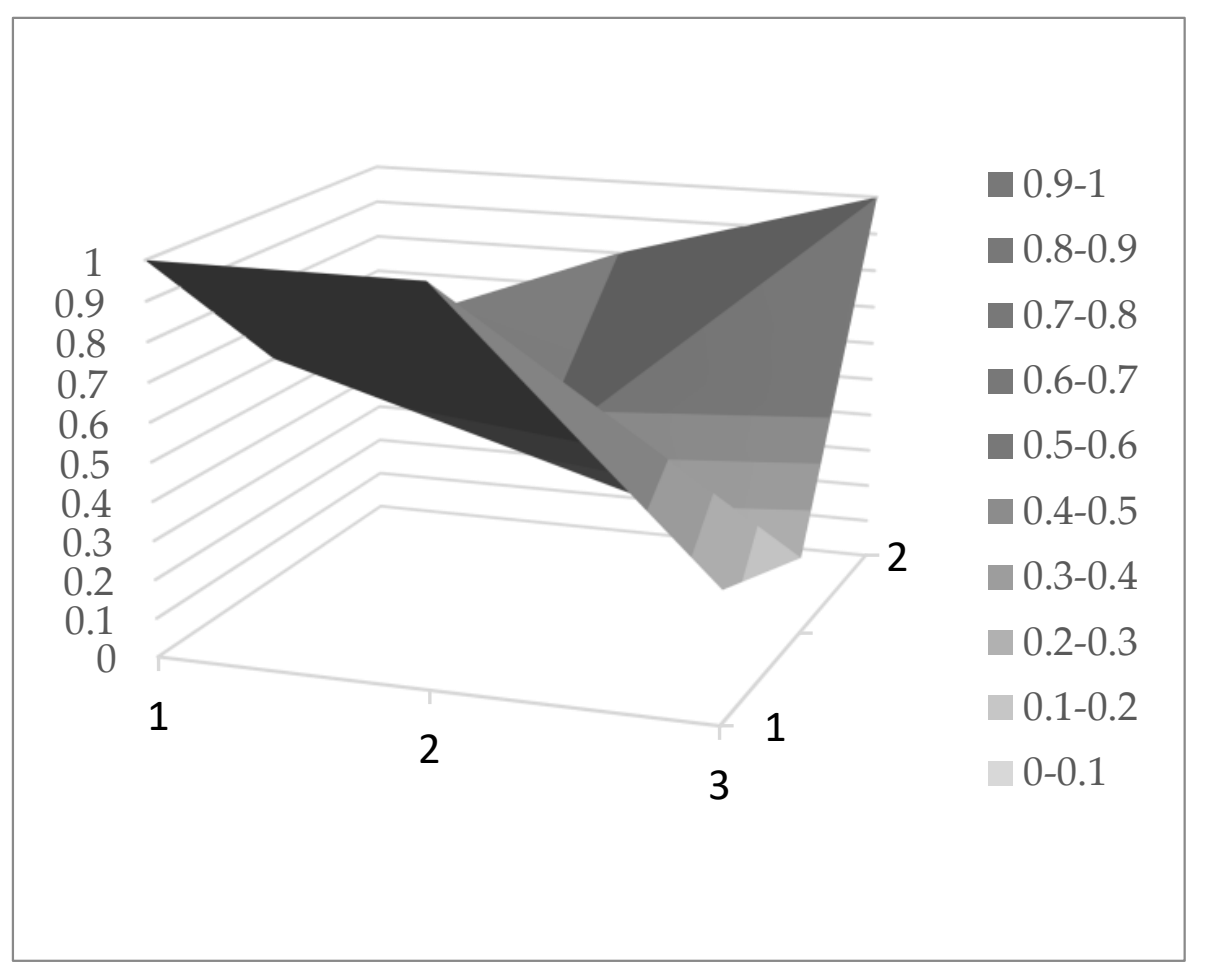

Figure 6. PMC surface of policy P1.

\subsection{Results and Discussion}

By examining the scores of each policy corresponding to the nine primary variables, weaknesses existing in each policy can be further identified as follows.

The mean score of X1 (issuing agency) is 0.94 , indicating that the authority level of the policy issuer is relatively high. This implies that local governments attach great importance to NIC policy formulation and release. All provinces or municipalities directly under the central government received the full score of 1, except for the score of 0.33 for Beijing. This is mainly because NIC policy in Beijing was issued by the Municipal Bureau of Economy and Informatization, while polices in other provinces were issued by the local government. The higher the authority level of policy issuer, the higher effectiveness of the policy implementation.

The average value of $\mathrm{X} 2$ (construction domain) is 0.83 , suggesting that the construction domain mentioned in polices for most local governments covers seven major fields. However, the score of five province in P2 is 0.71 , implying that these local governments are in dispute with the central government regarding the domain of NIC. Specifically, polices issued by P4 (Beijing), P11 (Guangdong), and P8 (Yunnan) did not involve ultra high voltage (UHV) line and intercity rail transit construction. Moreover, policy issued by P5 (Chongqing) did not cover UHV line and big data center construction. Policy released by P10 (Hubei) did not mention UHV line and construction of charging pile for new energy vehicles. As NIC in China is generally viewed as technology focused infrastructure upgrading, the scope of NIC and its construction domain need to be further clarified.

The mean score of X3 (policy time-span) is 0.33 and is relatively lower than the other eight primary variables. This is mainly attributed to the fact that the 12 NIC policies are designed using three-year rolling wave planning and do not have a medium- and long-term nature.

The average score of $X 4$ (supply-side incentive) is 0.87 . This shows that the 12 local governments have flexibly used a variety of supply-side policy tools to incentivize the providers and builders of new infrastructure. Relatively, the scores of P2 (Shanghai), P8 (Yunnan), and P10 (Hubei) are 0.80 owing to a lack of human and technical support incentives. The score of P11 (Guangdong) is 0.6 owing to a lack of project support and 
human and technical support incentives. The score of P9 (Sichuan) and P4 (Beijing) is 0.8 owing to a lack of project support incentives. The score of P1 (Jilin) is 0.6 owing to a lack of human and technical support as well as land and electricity support incentives.

The mean score of $\mathrm{X} 5$ (safeguard measures) is 0.87. This implies that these local governments attach great importance to the completeness of NIC safeguard measures. Nonetheless, the score of P9 (Sichuan) is 0.8 owing to a lack of measures for business environment improvements. Policies released in P7 (Fujian) and P8 (Yunnan) did not mention institutional regulations and received a score of 0.8 . The score of P3 (Jiangsu) is 0.6 , indicating no measures for institutional regulations and industrial layout. In addition, the score of P1 (Jilin) is 0.4, implying no measures for information security, business environment improvement, and industrial layout.

The average score of X6 (demand-side incentives) is 0.85 , suggesting that NIC policies issued by the 12 provinces (municipalities) also involved policy tools to incentivize the individual and business users' needs. The score of P1 (Jilin) is relatively low at 0.2 , indicating limited measures were used to stimulate infrastructure-based demand for digital application.

The mean score of $X 7$ (targeted actor) is relatively low at 0.62 . Specifically, policies issued in P1 (Jilin) and P3 (Jiangsu) received the lowest score of 0.43 , reflecting that the diversity of policy impact is limited. As discussed before, the technology-focused nature of the new infrastructure requires the collaborative participation of all kinds of organizations. The penetration of digital technology and applications into various industries also requires symbiosis and complementarity among different stakeholders. Extant NIC policy makers need to consider how to motivate many more stakeholders to devote to shaping an open and sustainable development ecosystem.

The average score of $\mathrm{X} 8$ (policy type) is near perfect at 0.98 . This reveals that NIC policy regulators in the 12 local governments took serious and comprehensive consideration and involved many aspects of policy planning, such as objective and scope definition, key performance designing, and action guidance, among others.

The mean score of $\mathrm{X} 9$ (policy rigorous) is 0.81 , indicating that most NIC polices have measurable actions, sound justification, and clear role and responsibility assignments. Only polices released in P7 (Fujian) and P8 (Yunnan) did not provide clear division of tasks and received a score of 0.67 .

\section{Conclusions and Future Directions}

As infrastructure investment proved to be a highly successful tool for China to stabilize economic activity during growth downturns in past years, the leading role of new infrastructure in the development of the digital economy has been paid increasingly more attention by different levels of authorities. Collecting 12 provincial NIC policies as data sources and using text mining and social network analysis method, this paper firstly reveals that Chinese governments adopt bottom-up incrementalism planning for the construction of new infrastructure. The central government outlines the high-level conception and the local authorities elaborate on the objective, scope, and organization of NIC according to the requirements of the infrastructure sustainability. This institutional arrangement is a kind of goal-oriented modulation; that is, on the one hand, it makes planning more adaptive (phased objectives with regard to outcomes) and participatory (open to stakeholders); on the other hand, because there are too many variables and uncertainties during the construction of new infrastructure and its enabled social development, it relies heavily on market forces and decentralized decision-making. The evaluation results of 12 provincial policies further reveal that most polices were evaluated as being of an excellent level based on the PMC index score. This shows that Chinese local governments attach great importance to NIC planning as it lays a solid foundation for the development of the regional digital economy. Various roles of the government acting as an initiator, a facilitator, and a mediator might maximize the possibilities for escalating economic and social sustainability by promoting innovation and mitigating negative effects. 
Our findings contribute to mission-oriented innovation policy that calls for a stronger role for policymakers in two ways. First, the policy steering mode of bottom-up incrementalism planning combines the advantages of top-down guidance and bottom-up experimentation through the use of shared vision and local rollout policy goals. Second, the construction of new infrastructure is an open-ended diffusion process that involve social actors and regulators. While infrastructure companies and policymakers are important actors, diffusion also requires the involvement of end users, solution providers, and other stakeholders throughout the construction and operation process. Therefore, co-creation and co-achievement mindsets are important for sustainable ecosystem development.

Based on these findings, several policy implications can be suggested as follows:

1. First, China's new infrastructure initiative can not only be viewed as convergence of application of digital technology with physical infrastructure, but also be regarded as the co-evolution process of large-scale innovation system and complex social system. As sustainable development is a continuous process of progressive social change, it often involves multiple interlinked evolutionary subsystems [32]. The co-evolutionary perspective provides a good way for thinking about policy agenda in the context of new infrastructure sustainable development. It implies that fragmented policies like science policy, innovation policy, and sector policy alone are not suited for dealing with social-technical complexity and desired long-term change. More types of governance, such as open, adaptive, and oriented towards learning and experimenting, are needed.

2. Second, different from the traditional top-down approach for physical infrastructure investment, China's bottom-up incrementalism planning for NIC is a mix of comprehensive planning (relying on full control) and incremental governance (relying on progressive steps and cycles of mutual learning and adaptation). The fundamental position of national infrastructure determines that its construction should not only adapt to the present, but also face the future, and it is not only necessary to promote the short-term gains, but also necessary to achieve the long-term goals. The bottom-up incrementalism planning aims to overcome the conflict between long-term imperatives (social and economic sustainability) and short-term concerns (technological and demand uncertainties). Although this policy steering mix is China context-specific, its inclusiveness and adaptive nature are generic.

One weakness of this research is that we only focus on the policy documents, rather than actual policy implementation. There might be a rhetoric-reality gap between policy expectation and its practice [33]. Past experiences show that, to release the policy is one thing, and to carry it out is another, as there will be many uncertainties arising in the implementation phases. Future research could be conducted to track and collect NIC-related investment data, and conduct the policy implementation evaluation to examine the impact of infrastructure projects or assets on regional digital technology development and industrial digitization. This could generate more insights into the co-evolution of government-led digital infrastructure crafting and sustainable digital economy development.

Author Contributions: Conceptualization: J.W.; Data curation: J.W. and Y.Z.; Formal Analysis: J.W., Y.Z. and Z.S.; Investigation: J.W.; Methodology: J.W. and Y.Z.; Project administration: J.W.; Resources: J.W.; Software: Y.Z. and Z.S.; Supervision: J.W.; Validation: J.W.; Visualization: Y.Z. and Z.S.; Writingoriginal draft: J.W., Y.Z. and Z.S.; Writing—review and editing: J.W. and Y.Z. All authors have read and agreed to the published version of the manuscript.

Funding: The APC was funded by the Institute of Service-Oriented Manufacturing (Hangzhou), China.

Institutional Review Board Statement: Not applicable.

Informed Consent Statement: Not applicable.

Data Availability Statement: Not applicable.

Conflicts of Interest: The authors declare no conflict of interest. 


\section{References}

1. Guo, C.; Xu, F. Research on New Infrastructure Promoting High Quality Development of the Belt and Road Construction. J. Xi'an Jiaotong Univ. 2020, 40, 1-10.

2. Liu, Y.; Huang, X.; Shi, B. China's New Infrastructure Construction: Concepts, Current Situations and Problems. J. Beijing Univ. Technol. 2020, 20,1-12.

3. Liu, Y.; Dong, J.; Wei, J. Digital Innovation Management: Theoretical Framework and Future Research. Manag. World 2020, $36,198-217,219$.

4. Li, X. New Infrastructure Construction and Policy Orientation for a Smart Society. Reform 2020, 05, 34-48. (In Chinese)

5. Guo, C.; Wang, J.; Liu, H. Studies on How New Infrastructure Empowers High-quality Development of China's Economy. J. Beijing Univ. Technol. 2020, 20, 13-21.

6. Weber, B.; Staub-Bisang, M.; Alfen, H.W. Infrastructure as an Asset Class: Investment Strategy, Sustainability, Project Finance and PPP; John Wiley \& Sons: Hoboken, NJ, USA, 2016.

7. Yoo, Y.; Henfridsson, O.; Lyytinen, K. Research commentary-the new organizing logic of digital innovation: An agenda for information systems research. Inf. Syst. Res. 2010, 21, 724-735. [CrossRef]

8. Tilson, D.; Lyytinen, K.; Sörensen, C. Research Commentary-Digital infrastructures: The missing IS research agenda. Inf. Syst. Res. 2010, 21, 748-759. [CrossRef]

9. Koutsikouri, D.; Lindgren, R.; Henfridsson, O.; Rudmark, D.; Viktoria, R. Extending Digital Infrastructures: A Typology of Growth Tactics. J. Assoc. Inf. Syst. 2018, 19, 1001-1019. [CrossRef]

10. Jiang, W.; Fan, J.; Zhang, X. "New Infrastructure" in China: Research on Investment Multiplier and Its Effect. Nanjing J. Soc. Sci. 2020, 4, 20-31.

11. Kang, J. New Infrastructure construction in China: Both urgent and long-term support. Int. J. Econ. Manag. Stud. 2020, 7, 49-54. [CrossRef]

12. Wan, J.; Zhao, L. On Basic Premises of Basic Research Policy Evaluation. Sci. Sci. Manag. S. T. 2009, 30, 5-11. (In Chinese)

13. Yang, T.; Xing, C.; Li, X. Evaluation and analysis of new-energy vehicle industry policies in the context of technical innovation in China. J. Clean. Prod. 2021, 281, 125126. (In Chinese) [CrossRef]

14. Wu, J.; Jiang Shang, Y.F.; Li, X. A Comparative Study of 5G Regional Policies in China: Content Analysis Using Policy Objectives, Tools, and Implementation Framework. J. Intell. 2020, 39, 104-112. (In Chinese)

15. Yang, T.; Lu, C.; Xue, Y.; Shan, M.; You, J. A PSOI Framework-based R\&D Internationalization Policy Study for Chinese Enterprises. Sci. Technol. Prog. Policy 2018, 35, 118-122. (In Chinese)

16. Rothwell, R.; Zegveld, W. An assessment of government innovation policies. Rev. Policy Res. 1984, 3, 436-444. [CrossRef]

17. Ruiz, E.M.A. Policy modeling: Definition, classification, and evaluation. J. Policy Modeling 2010, 33, 523-592. [CrossRef]

18. Xu, X.; Yin, X.; Ma, D. AHP-based Urban and Rural Household Registration System Reform Policy Evaluation Research. Northwest Popul. J. 2013, 34, 27-33, 38. (In Chinese)

19. Wang, X. An empirical study on performance evaluation of regional technology innovation policy-Based on perspective analysis of correlation and grey correlation. Sci. Res. Manag. 2014, 35, 3843. (In Chinese)

20. Li, J.; Chang, X. Innovation Policy Coordination of China's Circulation Industry. J. Bus. Econ. 2014, 09, 5-16. (In Chinese)

21. Guo, P.; Zhou, Y. A Grounded-theory-based Study on the Evaluation Index Extraction and Construction of China's City Green Transition Policy. Manag. Rev. 2018, 30, 257-267. (In Chinese)

22. Xue, Y.; Hu, L.; Feng, Y. Performance Evaluation of Science and Technology Innovation Policy in Inner Mongolia Based on Information Entropy and TOPSIS. World Sci. Tech. R. D. 2017, 39, 511-515.

23. Kuang, B.; Han, J.; Lu, X.; Zhang, X.; Fan, X. Quantitative evaluation of China's cultivated land protection policies based on the PMC-Index model. Land Use Policy 2020, 99, 105062. [CrossRef]

24. Li, Y.; He, R.; Liu, J.; Li, C.; Xiong, J. Quantitative Evaluation of China's Pork Industry Policy: A PMC Index Model Approach. Agriculture 2021, 11, 86. [CrossRef]

25. Zhang, Y.; Qie, H. The Quantitative Evaluation Research of Mass Entrepreneurship and Innovation-Based on Ten Dual Innovation Policies of 2017. J. Intell. 2018, 37, 158-164, 186. (In Chinese)

26. Zhao, L. Research on theoretical method of innovation policy evaluation-based on the evaluation framework of public policy evaluation. Stud. Sci. Sci. 2014, 32, 195-202. (In Chinese)

27. Ruiz, E.M.A.; Yap, S.F.; Nagaraj, S. Beyond the ceteris paribus assumption: Modeling demand and supply assuming omnia mobilis. Int. J. Econ. Res. 2008, 2, 185-194.

28. Sun, P.; Liu, M. On China's Urban Vulnerable Groups 'Tool Choice of Employment Policies-Based on an Analysis of Policy Texts. J. Northeast. Univ. 2017, 19, 595-601+615. (In Chinese)

29. Fan, Z.; Tan, H. Big Data Development Strategies of Chinese Local Governments Based on Documents Quantitative MethodsCompatibility of Policy Goals and Policy Tools. Chin. Public Adm. 2017, 12, 46-53. (In Chinese)

30. Du, B.; Zuo, Z. Quantitative Analysis of China's Scientific Research Integrity Policy Based on Data in the Period of 1999-2019. Sci. Technol. Manag. Res. 2020, 40, 252-259. (In Chinese)

31. Wang, F.; Yang, Q.; Zhang, Y. Quantitative Evaluation of Civil-Military Integration Policy Based on PMC-AE Index Model. J. Intell. 2019, 38, 66-73. (In Chinese) 
32. Kemp, R.; Loorbach, D.; Rotmans, J. Transition management as a model for managing processes of co-evolution towards sustainable development. Int. J. Sustain. Dev. World Ecol. 2007, 14, 78-91. [CrossRef]

33. Miao, J.T.; Maclennan, D. The rhetoric-reality gap of cities' success: Learning from the practice of Scottish cities. Reg. Stud. 2019, 53, 1761-1771. [CrossRef] 